\title{
A model of the evolution of the unusual sex chromosome system of Microtus oregoni
}

\author{
B. CHARLESWORTH* \& N. D. DEMPSEY \\ ICAPB, University of Edinburgh, Ashworth Laboratories, Edinburgh EH9 3JT, U.K.
}

\begin{abstract}
In the creeping vole, Microtus oregoni, females are X0 and males are XY. In the female germ line, mitotic nondisjunction ensures that the products of meiosis all carry the $\mathrm{X}$ chromosome. Similarly, mitotic nondisjunction in the male germ line leads to the production of 0 and $\mathrm{Y}$ sperm. We propose that the present situation in $M$. oregoni has evolved by invasion of a normal $\mathrm{XX} / \mathrm{XY}$ system by a mutant $\mathrm{X}$ chromosome, $\mathrm{X}^{\prime}$, with a complete transmission advantage in $\mathrm{X}^{\prime} \mathrm{X}$ females, and a complete transmission disadvantage in $X^{\prime} Y$ males. $X^{\prime}$ is at best initially nearly neutral, but can gain a transmission advantage if it reaches a high enough frequency. This is due to the production of $\mathrm{X} 0$ females in matings between $\mathrm{XX}$ females and $\mathrm{X}^{\prime} \mathrm{Y}$ males; low fertility and embryo loss of such females reduce the fitness of the $\mathrm{X}$ chromosome in females, relative to that of $\mathrm{X}^{\prime}$. Under some conditions, however, the enhanced reproductive value of males, caused by the production of inviable $\mathrm{Y} 0$ embryos in $\mathrm{X} 0 \times \mathrm{X}^{\prime} \mathrm{Y}$ matings, can outweigh any advantage to $\mathrm{X}^{\prime}$. Inbreeding also reduces any advantage to $\mathrm{X}^{\prime}$.
\end{abstract}

Keywords: inbreeding, segregation distortion, sex chromosomes, voles.

\section{Introduction}

Sex chromosome evolution has long attracted the attention of both cytogeneticists and evolutionary biologists (White, 1973; Bull, 1983). A major challenge has been the elucidation of the forces responsible for the evolution of dimorphic $\mathrm{X}$ and $\mathrm{Y}$ (or $\mathrm{Z}$ and $\mathrm{W}$ ) chromosomes, which are present in a wide range of taxa. While it cannot be claimed that this problem has been completely solved, a number of processes compatible with population genetics theory have been described, which seem likely to be involved in the evolution of such systems (Bull, 1983; Charlesworth, 1996; Rice, 1996; Charlesworth \& Charlesworth, 2000). In addition, possible paths by which an $\mathrm{XX} / \mathrm{XY}$ system can evolve into an $\mathrm{XX} / \mathrm{X} 0$ system, in which there is no $\mathrm{Y}$ chromosome left, have been suggested by Charlesworth (1996). There is also a body of theory relevant to the evolution of systems of neo-X and neo-Y chromosomes, formed by translocations or fusions between true sex chromosomes and autosomes (Charlesworth \& Charlesworth, 1980; Bull, 1983; Charlesworth, 1985; Charlesworth \& Wall, 1999). Certain cases of sex reversal in arvicolid rodents, such that some females in the population are XY instead of $\mathrm{XX}$, can be interpreted in terms of an associated transmission advantage (Bengtsson, 1977; Bull \& Bulmer, 1981; Bull, 1983; Fredga et al., 1993).

*Correspondence. E-mail: Brian.Charlesworth@ed.ac.uk
There are, however, several other sex chromosome systems which currently lack any evolutionary explanation. One of these is represented by the New Zealand species of frog, Liopelma hochstetteri, in which females are apparently $\mathrm{W} 0$ in constitution and males are 00 (Green, 1988). Another is that of the mole voles of the genus Ellobius, where several species have XX males and XX females (Fredga, 1983, 1994; Vogel et al., 1998). In E. lutescens, and in the Ammami spinous rat Tokudaia osumensis, both sexes appear to be X0 (Fredga, 1994). Finally, in the creeping vole, Microtus oregoni, females are $\mathrm{X} 0$ and males are $\mathrm{XY}$. In the female germ line, mitotic nondisjunction occurs, such that $\mathrm{XX}$ and 00 oogonia are produced. Only the former survive, so the products of meiosis are X egg cells. Similarly, in the male germ line mitotic nondisjunction causes the production of $\mathrm{XXY}$ and $\mathrm{OY}$ cells, of which only $0 \mathrm{Y}$ differentiate into spermatogonia, leading to 0 and $\mathrm{Y}$ sperm (Ohno et al., 1963, 1966; Fredga, 1994). The $M$. oregoni system is the subject of this paper.

\section{A model of M. oregoni}

\section{Cytogenetic assumptions}

One scenario to explain the $M$. oregoni system is through a mutation to a new type of $X, X^{\prime}$ say, in a conventional $\mathrm{XX} / \mathrm{XY}$ system, which causes the nondisjunction events described above. It seems reasonable to 
assume that such a mutation would have caused males to behave ab initio essentially as at present, such that 0 and $Y$ sperm of $X^{\prime} Y$ males are produced in equal frequencies. $X^{\prime}$ thus suffers a complete transmission disadvantage in males, which must be offset by a corresponding advantage in females if it is to spread in any but a very small population. There is no obvious difference between the $\mathrm{X}$ chromosome of $M$. oregoni and those of related species, other than a terminal deletion (Modi, 1987), so that there is no clue to the nature of the event that created the $\mathrm{X}^{\prime}$ chromosome.

In females, the $X^{\prime}$ chromosome must have been present initially in $X^{\prime} X$ individuals (even if the first $X^{\prime}$ female was $X^{\prime} 0$, matings with $X Y$ males would produce $\mathrm{X}^{\prime} \mathrm{X}$ daughters). The behaviour of this currently unobserved genotype must therefore be specified. The natural assumption is that $X^{\prime} X$ females produce a 1:1 ratio of $X^{\prime}$ to $\mathrm{X}$ eggs. But the lack of transmission advantage to $\mathrm{X}^{\prime}$ in females under this assumption means that $\mathrm{X}^{\prime}$ is always at a selective disadvantage (this has been confirmed by computer modelling; results not shown). An extreme alternative is to assume that $\mathrm{X}^{\prime} \mathrm{X}$ females produce only $\mathrm{X}^{\prime}$ gametes, i.e. there is effectively segregation distortion in favour of $\mathrm{X}^{\prime}$. This produces a transmission advantage that exactly balances the lack of transmission of $\mathrm{X}^{\prime}$ through males. We will assume this to be the case in what follows. Matings of $\mathrm{XX}$ females with $\mathrm{X}^{\prime} \mathrm{Y}$ males produce $\mathrm{X} 0$ females (Table 1); as shown below, the properties of $\mathrm{X} 0$ females play a critical role in the evolution of the system.

This assumption concerning the behaviour of $\mathrm{X}^{\prime} \mathrm{X}$ females raises two questions: (a) How could it happen at the level of cellular mechanisms? (b) What are the population dynamics of such an $\mathrm{X}^{\prime}$ chromosome? Our prime concern is with (b); we can only offer the following conjectures concerning (a). Assume that the kinetochore of the $\mathrm{X}^{\prime}$ chromosome is altered in some way that causes it to misalign with the spindle microtubules at a critical mitotic division during germline formation, so that the kinetochores of each $\mathrm{X}^{\prime}$ chromatid are attached to microtubules from the same spindle pole. Both $\mathrm{X}^{\prime}$

Table 1 Genetics of all possible matings ( $l$, lethal)

\begin{tabular}{lll}
\hline Mating type & \multicolumn{1}{c}{ Female progeny } & \multicolumn{1}{c}{ Male progeny } \\
\hline $1 \mathrm{XX} \times \mathrm{XY}$ & $\mathrm{XX}$ & $\mathrm{XY}$ \\
$2 \mathrm{X} 0 \times \mathrm{XY}$ & $k \mathrm{XX}:(1-k) \mathrm{X} 0$ & $k \mathrm{XY}:(1-k) \mathrm{Y} 0(l)$ \\
$3 \mathrm{X}^{\prime} \mathrm{X} \times \mathrm{XY}$ & $\mathrm{X}^{\prime} \mathrm{X}$ & $\mathrm{X}^{\prime} \mathrm{Y}$ \\
$4 \mathrm{X}^{\prime} 0 \times \mathrm{XY}$ & $\mathrm{X}^{\prime} \mathrm{X}$ & $\mathrm{X}^{\prime} \mathrm{Y}$ \\
$5 \mathrm{XX} \times \mathrm{X}^{\prime} \mathrm{Y}$ & $\mathrm{X} 0$ & $\mathrm{XY}$ \\
$6 \mathrm{X} 0 \times \mathrm{X}^{\prime} \mathrm{Y}$ & $k \mathrm{X} 0:(1-k) 00(l)$ & $k \mathrm{XY}:(1-k) \mathrm{Y} 0(l)$ \\
$7 \mathrm{X}^{\prime} \mathrm{X} \times \mathrm{X}^{\prime} \mathrm{Y}$ & $\mathrm{X}^{\prime} 0$ & $\mathrm{X}^{\prime} \mathrm{Y}$ \\
$8 \mathrm{X}^{\prime} 0 \times \mathrm{X}^{\prime} \mathrm{Y}$ & $\mathrm{X}^{\prime} 0$ & $\mathrm{X}^{\prime} \mathrm{Y}$ \\
\hline
\end{tabular}

chromatids will then move to the same pole at anaphase (Nicklas, 1997). If this alteration of the $X^{\prime}$ kinetochores also causes them to outcompete the kinetochores of the homologous $\mathrm{X}$ chromosome for some component involved in binding to the spindle microtubules, the $\mathrm{X}$ chromosome will fail to attach to the spindle and will be lost at cell division. A lack of similarity between the $\mathrm{X}$ and $\mathrm{Y}$ chromosome kinetochores would prevent this type of competition, and allow the pattern of segregation of $\mathrm{X}^{\prime}$ and $\mathrm{Y}$ seen in $\mathrm{X}^{\prime} \mathrm{Y}$ males.

A difficulty with these proposals is that the postulated misalignments of kinetochores in germline mitosis, and the lack of a pairing partner for the $\mathrm{Y}$ in male meiosis, would activate the cell cycle checkpoint that delays onset of anaphase in response to lack of tension on kinetochores (Nicklas, 1997; Taylor, 1999; Waters et al., 1999). However, as noted by Rieder et al. (1994) and Li \& Nicklas (1995), there is evidence that the checkpoint delays, but does not completely prevent, division if there are kinetochores that are not under tension. The successful completion of meiosis in $\mathrm{X} 0$ sex chromosome systems (Nicklas, 1997), and the systems of regular mitotic chromosome elimination via failure of chromosome attachment to the spindle in groups such as Cecidomyids (Nicklas, 1960), also show that the checkpoint is not an insuperable obstacle to the postulated behaviour of chromosomes in $\mathrm{X}^{\prime} \mathrm{X}$ and $\mathrm{X}^{\prime} \mathrm{Y}$ individuals of $M$. oregoni.

\section{Population genetic assumptions}

Question (b) has been tackled by means of simple algebra, and numerical calculations of the trajectories of populations with different starting frequencies of $\mathrm{X}^{\prime}$. The model allows for various levels of inbreeding, such that the proportion of matings between full-siblings is $\alpha$, the remainder being between unrelated individuals (Charlesworth \& Wall, 1999). In addition, we allow for reproductive compensation, i.e. a lack of reduction of litter size in proportion to the fraction of inviable embryos, in matings where lethal 00 or $\mathrm{Y} 0$ embryos are produced. Following Charlesworth (1994), the extent of reproductive compensation can be conveniently measured by a coefficient $C$, such that the litter size of matings with frequency $l$ of lethal embryos is multiplied by $(1-l)^{-C}$. If $C=1$, the litter size is completely unaffected by embryonic mortality; if $C=0$, litter size is proportional to the number of nonlethal embryos.

In addition, $\mathrm{X} 0$ house mice are known to exhibit unequal segregation of gametes. They produce a large excess of $\mathrm{XX}$ over $\mathrm{X} 0$ females in their progeny, more than can be explained by selective elimination of embryos alone (Cattanach, 1962). Direct observations 
of oocytes taken from $\mathrm{X} 0$ females has shown that $\mathrm{X}$ bearing eggs outnumber nullo-X eggs by almost 2:1 (Kaufman, 1972). There is thus a preferential loss of nullo-X oocytes during oogenesis. Although no direct evidence is available, it is possible that a similar phenomenon may have occurred among the $\mathrm{X} 0$ females postulated to have been present during the evolution of the $M$. oregoni system. This segregation distortion can be represented by setting the frequency of $X$ among the eggs of $\mathrm{X} 0$ females to $k \geq 0.5$.

We assume that there are no genotypic effects on viability, other than the lethality of 00 and Y0 embryos, and no effects on male fertility. But it is likely that some genotypic effects on female fertility must be allowed for. It has long been known that X0 house mice are viable and fertile. However, their reproductive lifespan is approximately half that of XX females (Cattanach, 1962; Morris, 1968). Mean litter size is greatly reduced, to $55 \%$ of that for $\mathrm{XX}$ females, and the mean total number of offspring produced by an $\mathrm{X} 0$ female mouse is $34 \%$ of that produced by XX mice (Lyon \& Hawker, 1973). These effects are most likely caused by a combination of three factors: reduced secretion of gonadotrophic hormones, lower numbers of primordial germ cells, and pre- and post-implantation loss of embryos (Dyban \& Baranov, 1987). The reproductive biology of arvicolid rodents is obviously rather different from that of mice (Tamarin, 1985; Stenseth \& Ims, 1993), and so it is uncertain whether this fertility reduction applies to them. Limited data on the wood lemming Myopus schisticolor indicate that $\mathrm{X} 0$ females can be fertile (Fredga et al., 1993), but no quantitative measure of their relative fertility seems to be available. For completeness, we thus allow the fertility of $\mathrm{X} 0$ M. oregoni to differ from that of XX, representing their relative fertility (in terms of their mean lifetime production of embryos, before selective loss of $\mathrm{Y} 0$ progeny) by $f_{2}$. Since $X^{\prime} X$ and $X^{\prime} 0$ females do not produce X0 germ cells, it is unlikely that they will differ from XX females, but our general model assigns them relative fertilities of $f_{3}$ and $f_{4}$, respectively.

Because of the non-Mendelian ratios produced in this system, the usual assumption of Hardy-Weinberg genotype frequencies cannot be made, even with random mating. The system is thus represented in terms of the frequencies of different types of matings, e.g. $\mathrm{XX} \times \mathrm{XY}$, $X^{\prime} X \times X Y$, etc. (Table 1). These form components of a vector, $\mathrm{z}$, such that the $i$ th component of $\mathrm{z}, z_{i}$, corresponds to the ith mating type in Table 1. The frequencies of segregants shown in Table 1 enable a set of recursion relations to be obtained that describes the transition from one generation to the next, which are given in the Appendix.

\section{Results}

\section{Analytic results}

Before describing the detailed results of numerical investigations of these recursions, some useful conclusions derived from the study of special cases will be presented. First, we consider the conditions for the initial increase of $\mathrm{X}^{\prime}$ when introduced into a randomly mating $\mathrm{XX} / \mathrm{XY}$ population at a low frequency. If second-order terms in the frequency of $\mathrm{X}^{\prime}$ are neglected, only two types of mating involving genotypes with $\mathrm{X}^{\prime}$ need be considered: $\mathrm{X}^{\prime} \mathrm{X} \times \mathrm{XY}$ and $\mathrm{XX} \times \mathrm{X}^{\prime} \mathrm{Y}$. From Table 1, it is easy to see that, to this order of approximation, the sum of the frequencies of these matings is constant, since the transmission advantage of $\mathrm{X}^{\prime}$ in females is cancelled by its disadvantage in males (assuming that $f_{3}=1$ ). Hence, $\mathrm{X}^{\prime}$ changes in frequency when rare at a rate that is at most second-order in its frequency, unless $\mathrm{X}^{\prime} \mathrm{X}$ females have altered fertility. Inbreeding does not significantly modify this conclusion, since its effect is to allow $\mathrm{X}^{\prime} \mathrm{X}$ or $\mathrm{X}^{\prime} 0$ females to mate with $X^{\prime} Y$ males. Since these matings result in a 1:1 ratio of $\mathrm{X}^{\prime} 0$ to $\mathrm{X}^{\prime} \mathrm{Y}$ progeny, there is no fitness advantage over $\mathrm{XX} \times \mathrm{XY}$ matings, at least to first-order terms in the frequency of $X^{\prime}$, if the fertility of $X^{\prime} 0$ females is the same as that of $\mathrm{XX}$ females.

Thus, the geometric rate of change in frequency of $X^{\prime}$ will be expected to be zero, if $X^{\prime}$ is sufficiently rare and it does not affect fitness directly. But if $X^{\prime}$ reaches a sufficiently high frequency, its effects on mating types other than those just considered will start to influence its dynamics. The fact that its presence in males causes the formation of $\mathrm{X} 0$ females promotes the spread of $\mathrm{X}^{\prime}$. The low fertility of $\mathrm{X} 0$ females and/or the loss of embryos among the litters they produce reduces their contribution to the next generation, favouring $\mathrm{X}^{\prime}$ over $\mathrm{X}$. An opposite effect arises from the fact that the presence of $\mathrm{X} 0$ females enhances the reproductive value of male vs. female progeny. This is because $\mathrm{X} 0 \times \mathrm{XY}$ matings have a deficiency of male progeny, due to the lethality of $\mathrm{Y} 0$ embryos, unless there is complete segregation distortion. Since $\mathrm{X}^{\prime}$ is not transmitted through males, the greater reproductive value of males reduces its net fitness relative to $X$. This negative effect is strongest with a high level of reproductive compensation and when $k$ is close to 0.5 , since this maximizes the reduction in the proportion of males in the whole population. Thus, unless the fertility of $\mathrm{X} 0$ females is low enough to overcome this negative effect, $\mathrm{X}^{\prime}$ can be at a selective disadvantage at intermediate frequencies, if $C$ is sufficiently high and $k$ is sufficiently low.

It is straightforward to analyse the dynamics of the system when $\mathrm{X}$ is introduced at a low frequency into a 
randomly mating $X^{\prime} X / X^{\prime} Y$ population. The only relevant mating types involving $X$ are $X 0 \times X^{\prime} Y$, $\mathrm{X}^{\prime} \mathrm{X} \times \mathrm{XY}$, and $\mathrm{X}^{\prime} 0 \times \mathrm{XY}$ (matings between $\mathrm{XX}$ and $\mathrm{X}^{\prime} \mathrm{Y}$ generate $\mathrm{X} 0$ females, so that $\mathrm{X}$ in females is always associated with 0 after one generation). We obtain the following recursion relations:

$z_{4}^{\prime}=z_{7} f_{3} / f_{4}$

$z_{6}^{\prime}=z_{6} f_{2} k^{1}{ }^{C} / f_{4}$

$z_{7}^{\prime}=z_{4}$

It easily seen that this system has eigenvalues of $f_{2} k^{1-C} / f_{4}$, $\sqrt{ } f_{3} / f_{4}$ and $-\sqrt{ } f_{3} / f_{4}$. If $f_{3}=f_{4}$, a population fixed for $\mathrm{X}^{\prime}$ will be stable to the introduction of $\mathrm{X}$ if and only if

$f_{2} k^{1} \quad C / f_{4}<1$.

This implies that fixation of $\mathrm{X}^{\prime}$ is always stable under random mating if $\mathrm{X} 0$ females have lower fertility than $\mathrm{X}^{\prime} 0$ females. Low values of $k$ and $C$ provide the strongest selective advantage to $\mathrm{X}^{\prime}$ over $\mathrm{X}$. If compensation is complete, a fertility disadvantage to $\mathrm{X} 0$ females is a necessary condition for an advantage to $\mathrm{X}^{\prime}$. If there is inbreeding, we expect this advantage to be diminished, since $\mathrm{XX} \times \mathrm{XY}$ matings now play a role, and are neutral relative to $\mathrm{X}^{\prime} 0 \times \mathrm{X}^{\prime} \mathrm{Y}$.

\section{Numerical results}

The above conclusions were confirmed by numerical results derived from iterations of the general set of recursion relations. The upper panel of Table 2 shows the case of a population with no compensation and with $k=0.5$, with varying levels of inbreeding and initial frequencies of $\mathrm{X}^{\prime}$. As expected, even under this relatively favourable case for the spread of $X^{\prime}$, its initial geometric rate of spread is negligible if it is very rare. But if $X^{\prime}$ is present at a sufficiently high frequency, it can spread rapidly if the level of inbreeding is low, even if there is no fertility disadvantage to $\mathrm{X} 0$ females. The lower panel shows the corresponding situation for $\mathrm{X}$ introduced into an $\mathrm{X}^{\prime}$ population; even for as much as $50 \%$ sib-mating, invasion by $\mathrm{X}$ is strongly resisted by selection.

Table 3 shows the effect of varying the fertility of $\mathrm{X} 0$ females, the degree of segregation distortion among their progeny, and the level of reproductive compensation on the rate of spread of $\mathrm{X}^{\prime}$ when introduced at a low frequency into a population fixed for $\mathrm{X}$. Table 4 is a similar study of the effects of these parameters on the ability of $\mathrm{X}$ to invade an $\mathrm{X}^{\prime}$ population. The results
Table 2 Effects of initial mutation frequency and inbreeding

A. Results of introducing $X^{\prime}$ into an $X$ population. Values indicate numbers of generations until $\mathrm{X}^{\prime}$ frequency exceeds 0.99

\begin{tabular}{lcccc}
\hline $\begin{array}{l}\text { Initial } \mathrm{X}^{\prime} \\
\text { frequency }\end{array}$ & $\alpha=0$ & $\alpha=0.2$ & $\alpha=0.8$ & $\alpha=0.9$ \\
\hline $5 \times 10^{-5}$ & Neutral & Neutral & Neutral & Neutral \\
$5 \times 10^{-4}$ & 503000 & 989000 & Neutral & Neutral \\
0.005 & 5140 & 10000 & 641000 & Neutral \\
0.0025 & 247 & 470 & 28500 & 227000 \\
0.05 & 83 & 153 & 8470 & 66700 \\
0.25 & 16 & 29 & 1180 & 8540 \\
\hline
\end{tabular}

B. Results of introducing a normal $X$ into an $X^{\prime}$ population. Values indicate numbers of generations until $\mathrm{X}$ chromosome frequency is one-tenth the initial level

\begin{tabular}{lcccc}
\hline $\begin{array}{l}\text { Initial X } \\
\text { frequency }\end{array}$ & $\alpha=0$ & $\alpha=0.2$ & $\alpha=0.8$ & $\alpha=0.9$ \\
\hline $1 \times 10^{-4}$ & 6 & 13 & 584 & 4177 \\
0.001 & 6 & 13 & 583 & 4168 \\
0.01 & 6 & 13 & 585 & 4188 \\
0.1 & 7 & 14 & 615 & 4428 \\
0.5 & 9 & 18 & 906 & 6865 \\
\hline
\end{tabular}

$C=0, k=0.5, f_{2}=f_{3}=f_{4}=1$.

See text for further explanation.

confirm the conclusions reached above; it will be seen that there are parameter sets in which the spread of $X^{\prime}$ from a low frequency is resisted, despite the stability of an $\mathrm{X}^{\prime}$ population against invasion by $\mathrm{X}$. This indicates the existence of an unstable equilibrium with an intermediate frequency of $\mathrm{X}^{\prime}$.

\section{Discussion}

We have assumed that the present situation in $M$. oregoni has evolved through invasion of a normal $\mathrm{XX} / \mathrm{XY}$ system by a mutant $\mathrm{X}$ chromosome, $\mathrm{X}^{\prime}$, with a complete transmission advantage in $X^{\prime} X$ females, and a complete transmission disadvantage in $\mathrm{X}^{\prime} \mathrm{Y}$ males. Our results show that $\mathrm{X}^{\prime}$ is at best initially nearly neutral, but can gain a transmission advantage if it reaches a high enough frequency, under suitable conditions. This is due to the production of $\mathrm{X} 0$ females in matings between $\mathrm{XX}$ females and $X^{\prime} Y$ males; the low fertility and embryo loss for such females reduce the fitness of the $\mathrm{X}$ chromosome in females, relative to that of $\mathrm{X}^{\prime}$. But the enhanced reproductive value of males, caused by the production of inviable $\mathrm{Y} 0$ embryos in $\mathrm{X} 0 \times \mathrm{X}^{\prime} \mathrm{Y}$ matings, can outweigh any advantage to $\mathrm{X}^{\prime}$, if compensation is high enough and there is a low level of segregation distortion. 
Table 3 Effects of reproductive compensation, unequal gamete segregation and reduced fertility of $\mathrm{X} 0$ females on $\mathrm{X}^{\prime}$ fixation

\begin{tabular}{ccccccc}
\hline & & \multicolumn{5}{c}{$f_{2}$} \\
\cline { 3 - 7 }$C$ & $k$ & 0.1 & 0.3 & 0.7 & 0.9 & 1.0 \\
\hline 0 & 0.5 & 120 & 137 & 232 & 518 & 5138 \\
& 0.6 & 121 & 141 & 257 & 613 & 7690 \\
& 0.7 & 122 & 146 & 283 & 713 & 11900 \\
& 0.8 & 123 & 151 & 310 & 823 & 20500 \\
& 0.9 & 125 & 156 & 338 & 945 & 46000 \\
& 1.0 & 126 & 160 & 367 & 1093 & Neutral \\
0.5 & 0.5 & 121 & 142 & 324 & - & - \\
& 0.6 & 122 & 146 & 334 & - & - \\
& 0.7 & 123 & 150 & 343 & 2408 & - \\
& 0.8 & 124 & 154 & 352 & 1518 & - \\
& 0.9 & 125 & 157 & 360 & 1227 & - \\
& 1.0 & 126 & 160 & 367 & 1093 & Neutral \\
0.95 & 0.5 & 122 & 149 & 659 & - & - \\
& 0.6 & 123 & 152 & 504 & - & - \\
& 0.7 & 124 & 155 & 440 & - & - \\
& 0.8 & 125 & 157 & 405 & 10150 & - \\
& 0.9 & 125 & 159 & 383 & 1700 & - \\
& 1.0 & 126 & 160 & 367 & 1093 & Neutral \\
\hline
\end{tabular}

Values indicate number of generations until $\mathrm{X}^{\prime}$ frequency exceeds 0.99 from an initial frequency of 0.01 .

- indicates selection against $\mathrm{X}^{\prime}$.

$f_{3}=f_{4}=1$.

Furthermore, inbreeding reduces any advantage to $X^{\prime}$; in the extreme case of complete inbreeding, $\mathrm{X}^{\prime}$ is neutral. If inbreeding is not complete, an $\mathrm{X}^{\prime}$ population can always resist invasion by $X$, unless compensation and segregation distortion are complete and there is no fertility disadvantage of $\mathrm{X} 0$ females.

We have therefore succeeded in providing a set of population genetic conditions under which the evolution of the $M$. oregoni system is no longer mysterious. Given the evidence from house mice concerning the low fertility of X0 females (Lyon \& Hawker, 1973), there seems to be a strong possibility that a mutant $\mathrm{X}$ chromosome could start to spread once it reaches a sufficiently high frequency. Division of the species into partially isolated subpopulations of small size would allow genetic drift to produce a locally high frequency of $\mathrm{X}^{\prime}$, and hence trigger its spread by selection. While there are apparently no data on the population structure of $M$. oregoni, a study of the related European species M. oeconomus (Leijs et al., 1999) provides evidence for high levels of genetic differentiation as measured by $F_{\mathrm{ST}}$ for enzyme markers between local populations. This is in accordance with the evidence from many other studies of small rodent
Table 4 Effects of reproductive compensation, unequal gamete segregation and reduced fertility of $\mathrm{X} 0$ females on introduction of normal $\mathrm{X}$ into an $\mathrm{X}^{\prime}$ population

\begin{tabular}{lcccccc}
\hline & & \multicolumn{5}{c}{$f_{2}$} \\
\cline { 3 - 6 }$C$ & $k$ & 0.1 & 0.3 & 0.7 & 0.9 & 1.0 \\
\hline 0 & 0.5 & 4 & 4 & 5 & 6 & 6 \\
& 0.6 & 4 & 5 & 6 & 7 & 8 \\
& 0.7 & 4 & 5 & 7 & 9 & 11 \\
& 0.8 & 4 & 5 & 8 & 11 & 16 \\
& 0.9 & 4 & 5 & 9 & 17 & 31 \\
& 1.0 & 5 & 6 & 11 & 31 & Neutral \\
0.5 & 0.5 & 4 & 5 & 7 & 9 & 11 \\
& 0.6 & 4 & 5 & 7 & 11 & 14 \\
& 0.7 & 4 & 5 & 8 & 13 & 19 \\
& 0.8 & 4 & 5 & 9 & 16 & 29 \\
& 0.9 & 4 & 5 & 10 & 21 & 59 \\
& 1.0 & 5 & 6 & 11 & 31 & Neutral \\
0.95 & 0.5 & 5 & 5 & 10 & 24 & 92 \\
& 0.6 & 5 & 5 & 11 & 26 & 124 \\
& 0.7 & 5 & 5 & 11 & 27 & 177 \\
& 0.8 & 5 & 5 & 11 & 28 & 282 \\
& 0.9 & 5 & 5 & 11 & 30 & 594 \\
& 1.0 & 5 & 6 & 11 & 31 & Neutral \\
\hline
\end{tabular}

$\mathrm{X}$ chromosome is introduced at low frequency; initial frequency of mating type $6=0.01$.

Values indicate number of generations until X chromosome frequency is one tenth the initial level.

populations (e.g. Dallas et al., 1995). A direct test on $M$. oregoni is clearly desirable.

Our model also suggests that a high level of close inbreeding, as distinct from population subdivision, is unlikely to be compatible with the spread of $X^{\prime}$, although it is quite robust to levels of sib-mating of up to $50 \%$. Examination of the level of inbreeding in $M$. oregoni populations could be carried out relatively easily, by estimating $F_{\text {IS }}$. Estimates of $F_{\text {IS }}$ in $M$. agrestis (Frykman, 1988) and M. oeconomus (Leijs et al., 1999) do not suggest high levels of inbreeding in these species.

These population genetic conclusions do not, of course, provide any insights into how a change in the $\mathrm{X}$ chromosome can produce the suite of characteristics that appear to be necessary for the system to evolve. This is a challenge to cell biologists.

Our model may not, of course, be the only possible path by which this system has evolved, but it does have the merit of invoking only a single chromosomal mutation. Other possibilities would seem to require at least two changes in quick succession. For example, a reviewer has suggested the following alternative scenario. A Y chromosome causing meiotic drive arises, 
and spreads rapidly through the population, inducing a highly male-biased sex ratio (Hamilton, 1967). A mutation to an $\mathrm{X}^{\prime}$ chromosome arises, which causes the observed mitotic nondisjunction in $\mathrm{X}^{\prime} 0$ females and in males, but has no effect on $\mathrm{X}^{\prime} \mathrm{X}$ females. $\mathrm{X}^{\prime} 0$ progeny produced by matings of $\mathrm{X}^{\prime}$-carrying males with $X^{\prime} X$ females will produce a 1:1 sex ratio when mated to $X^{\prime}$ males with a driving $Y$. If the sex ratio is highly male biased, the resulting very high reproductive value of female progeny could nearly overcome the transmission disadvantage to $\mathrm{X}^{\prime}$ in males and any fertility disadvantage to $X^{\prime} 0$ females. The problems with this model are: first, there is a requirement for the mutation to $\mathrm{X}^{\prime}$ to spread before the driving $\mathrm{Y}$ has reached such a high frequency that the species goes extinct. Second, the most likely matings when $\mathrm{X}^{\prime}$ is rare are between $\mathrm{XX}$ females and $\mathrm{X}^{\prime} \mathrm{Y}$ males, which disfavour $X^{\prime}$. A high level of inbreeding is thus needed, so that there is a good chance that an $X^{\prime} X$ female mates with a driving male with an $\mathrm{X}^{\prime}$ chromosome, otherwise $\mathrm{X}^{\prime}$ will be eliminated. This is in contrast to the prediction of the model we are proposing.

It is difficult to devise conclusive tests of our model, since it depends on the properties of $\mathrm{X}^{\prime} \mathrm{X}$ females, which can no longer be observed. The extensive chromosomal differences between New World species of Microtus (Gaines, 1985; Modi, 1987) probably preclude intercrossing of $M$. oregoni with other species, to create $\mathrm{X}^{\prime} \mathrm{X}$ females, despite the evidently very recent radiation of this group (Chaline, 1987; Modi, 1996). A possible approach is through comparative studies of molecular variation on the $\mathrm{X}$ chromosome in $M$. oregoni and its relatives. On our model, the $\mathrm{X}^{\prime}$ chromosome is transmitted entirely without the opportunity to cross over with a homologue, whereas alternative scenarios where $\mathrm{X}^{\prime}$ undergoes meiosis in company with a normal $\mathrm{X}$ would allow crossing-over between the two chromosomes. On our model, the whole $\mathrm{X}^{\prime}$ chromosome thus behaves as a non-recombining block, and its spread would therefore eliminate variability at marker loci as a result of the hitch-hiking event (Maynard Smith \& Haigh, 1974; Charlesworth \& Charlesworth, 1998). Given the recent origin of the species group to which $M$. oregoni belongs (Chaline, 1987; Modi, 1996), there should be little opportunity for variation to have been regained by mutation, resulting in a sharp reduction in the level of variability at $\mathrm{X}$ chromosomal loci in $M$. oregoni, compared with loci on other chromosomes. In contrast, the model which invokes a driving $\mathrm{Y}$ chromosome predicts no generalized reduction in variation on the $\mathrm{X}$ chromosome, except as a result of hitch-hiking events or background selection effects (Maynard Smith \& Haigh,
1974; Charlesworth \& Charlesworth, 1998) that took place after the establishment of the current system, but there should be a sharp reduction in variation on the $\mathrm{Y}$ chromosome. A lack of signature of a hitch-hiking effect on the $\mathrm{X}$ chromosome, coupled with evidence for one on the $\mathrm{Y}$, would falsify the predictions of our model.

\section{Acknowledgements}

We thank B. O. Bengtsson, J. F. Y. Brookfield and three anonymous reviewers for their comments on the manuscript. ND and BC are supported by the Royal Society.

\section{References}

BENGTSSON, B. O. 1977. Evolution of the sex ratio in the wood lemming, Myopus schisticolor. In: Christiansen, F. B. and Fenchel, T. M. (eds) Measuring Selection in Natural Populations, pp. 333-343. Springer, Berlin.

BULl., J. J. 1983. Evolution of Sex Determining Mechanisms. Benjamin Cummings, Menlo Park, CA.

BULl., J. J. AND BULMer, M. G. 1981. The evolution of XY females in mammals. Heredity, 47, 347-365.

CATTANACH, B. M. 1962. XO mice. Genet. Res., 3, 487-490.

CHAline, J. 1987. Arvicolid data (Arvicolidae, Rodentia) and Evolutionary Concepts. In: Hecht, M. K., Wallace, B. and Prance, G. T. (eds) Evolutionary Biology, 21, 237-310, Plenum, New York.

CHARLESWORTH, B. 1985. Recombination, genome size and chromosome number. In: Cavalier-Smith, T. (ed.) The Evolution of Genome Size, pp. 489-513. John Wiley, Chichester, U.K.

CHARLESWORTH, B. 1994. The evolution of lethals in the $t$-haplotype system of the mouse. Proc. R. Soc. B, 258, 101-107.

CHARLESWORTH, B. 1996. The evolution of chromosomal sex determination and dosage compensation. Curr. Biol., 6, 149-162.

CHARLESWORTH, B. AND CHARLESWORTH, D. 2000. The degeneration of Y chromosomes. Phil. Trans. R. Soc. B., 355, 1851-1864.

CHARLESWORTH, B. AND WALL, J. D. 1999. Inbreeding, heterozygote advantage and the evolution of neo-X and neo-Y chromosomes. Proc. R. Soc. B., 266, 51-56.

CHARlesworth, D. AND CHARLESWORTH, B. 1980. Sex differences in fitness and selection for centric fusions between the sex chromosomes. Genet. Res., 35, 205-214.

CHARlesworth, D. AND. CHARlesworth, B. 1998. Sequence variation: looking for effects of genetic linkage. Curr. Biol., 8, R658-R661.

DAllas, J. F., DOEL, B., BOURSOT, P., PRAGER, E. M. ET AL. 1995. Population subdivision and gene flow in Danish house mice. Mol. Ecol., 4, 311-320.

DYBAN, A. P. AND BARANOV, V. S. 1987. Cytogenetics of Mammalian Embryonic Development. Oxford University Press, Oxford. 
FREDGA, K. 1983. Aberrant sex chromosome mechanisms in mammals. Evolutionary aspects. Differentiation (Suppl.), 23, S23-S30.

FREDGA, K. 1994. Bizarre mammalian sex-determining mechanisms. In: Short, R. V. and Balaban, E. (eds) The Differences Between the Sexes, pp. 397-418. Cambridge University Press, Cambridge, U.K.

FREDGA, K., FREDRIKSSON, R., BONDRUP-NIELSEN, S. AND IMS, R. A. 1993. Sex ratio, chromosomes and isozymes in natural populations of the wood lemming (Myopus schisticolor). In: Stenseth, N. C. and Ims, R. A. (eds) The Biology of Lemmings, pp. 465-491. Linnaean Society, London.

FRYKMAN, I. 1988. Breeding structure in two field vole populations. Hereditas, 108, 41-46.

GAINES, M. S. 1985. Genetics. In: Tamarin, R. H. (ed.) Biology of New World Microtus, pp. 845-883. American Society of Mammalogists, Special Publication no. 8, Shippensburg, PA. GREEN, D. M. 1988. Cytogenetics of the endemic New Zealand frog Liopelma hochstetteri: extraordinary chromosome variation and a unique sex-chromosome system. Chromosoma, 97, 55-70.

HAMilton, w. D. 1967. Extraordinary sex ratios. Science, 156, 477-488.

KAUfMAN, M. H. 1972. Non-random segregation during mammalian oogenesis. Nature, 238, 465-466.

LEIJS, R., VAN APPELDOORN, E. AND BIJLSMA, R. 1999. LOW genetic differentiation in north-west European populations of the locally endangered root vole Microtus oeconomus. Biol. Conserv., 87, 39-48.

LI, X. AND NICKLAS, R. B. 1995. Mitotic forces control a cell-cycle checkpoint. Nature, 373, 60-632.

LYON, M. F. AND HAWKER, S. G. 1973. Reproductive lifespan in irradiated and unirradiated chromosomally XO mice. Genet. Res., 21, 125-137.

MAYNARD SMITH, J. AND HAIGH, J. 1974. The hitch-hiking effect of a favourable gene. Genet. Res., 23, 23-35.

MODI, w. S. 1987. Phylogenetic analyses of chromosomal banding patterns among the Nearctic Arvicolidae (Mammalia: Rodentia). Syst. Zool., 36, 109-136.

\section{Appendix: Recursion relations for the general model}

Let $p=([1+k] / 2)^{-C}$ and $q=k^{-C}$ be the effect of compensation on the sizes of litters of types 2 and 6 of Table 1, respectively. Inspection of Table 1 yields the following set of expressions for the (unnormalized) genotype frequencies of $\mathrm{XX}, \mathrm{X} 0, \mathrm{X}^{\prime} 0, \mathrm{X}^{\prime} \mathrm{X}$ and $\mathrm{X}^{\prime} 0$, respectively, among females (weighted by their fertilities):

$x_{1}=z_{1}+p k z_{2}$

$x_{2}=f_{2}\left(p[1 \quad k] z_{2}+z_{5}+q k z_{6}\right)$

$x_{3}=f_{3}\left(z_{3}+z_{4}\right)$
MODI, w. S. 1996. Phylogenetic history of LINE-1 among arvicolid rodents. Mol. Biol. Evol., 13, 633-641.

MORRIS, T. 1968. The XO and OY chromosome constitution in the mouse. Genet. Res., 12, 125-137.

NICKLAS, R. B. 1960. The chromosome cycle of a primitive cecidomyid- Mycophila speyeri. Chromosoma, 11, 402-418.

NICKLAS, R. B. 1997. How cells get the right chromosomes. Science, 275, 633-637.

OHNO, S., JAINCHILL, J. AND STENIUS, C. 1963. The creeping vole (Microtus oregoni) as a gonosomic mosaic. I. The $0 \mathrm{y} / \mathrm{XY}$ constitution of the male. Cytogenetics, 2, 232-239.

OHNO, S., STENIUS, C. H. AND CHRISTIAN, L. 1966. The X0 as the normal female of the creeping vole (Microtus oregoni). In: Darlington, C. D. and Lewis, K. R. (eds) Chromosomes Today, vol. 1, pp. 182-187. Oliver and Boyd, Edinburgh.

RICE, W. R. 1996. Evolution of the Y sex chromosome in animals. Biosciences, 46, 331-343.

RIEDER, C. L., SChultz, A., COLE, R. AND SLudER, G. 1994. Anaphase onset in vertebrate somatic cells is controlled by a checkpoint that monitors kinetochore attachment to the spindle. J. Cell. Biol., 127, 1301-1310.

STENSETH, N. C. AND IMS, R. A. 1993. The Biology of Lemmings. Linnaean Society, London.

TAMARIN, R. H. 1985. Biology of New World Microtus. American Society of Mammalogists, Special Publication no. 8, Shippensburg, PA.

TAYLOR, S. S. 1999. Chromosome segregation: dual control ensures fidelity. Curr. Biol., 9, R562-R564.

vogel, W., JAInTA, S., RAU, W., GeERKens, C. ET $A$ L. 1998. Sex determination in Ellobius lutescens: the story of an enigma. Cytogenet. Cell. Genet., 80, 214-221.

WATERS, J. C., CHEN, R.-H., MURRAY, A. W., GORBSKY, G. J. ET AL. 1999. Mad2 binding by phosphorylated kinetochores links error detection and checkpoint action in mitosis. Curr. Biol., 9, 649-652.

white, M. J. D. 1973. Animal Cytology and Evolution, 3rd edn. Cambridge University Press, Cambridge.

$x_{4}=f_{4}\left(z_{7}+z_{8}\right)$.

Similarly, the frequencies of $\mathrm{XY}$ and $\mathrm{X}^{\prime} \mathrm{Y}$ among males are given by:

$y_{1}=z_{1}+p k z_{2}+z_{5}+q k z_{6}$

$y_{2}=z_{3}+z_{4}+z_{7}+z_{8}$.

These can be used to generate a vector $r$ of contributions from random matings to the new vector of mating type frequencies, such that $r_{i}=x_{i} \mathrm{y}_{1}$ and $r_{i}+4=x_{i} \mathrm{y}_{2}$ $(i=1$ to 4$)$.

From Table 1, a similar vector, s, of contributions from sib-matings can be defined. The only non-zero components are: 


$$
\begin{aligned}
& s_{1}=z_{1}+p k z_{2} \\
& s_{2}=f_{2}\left(p\left[\begin{array}{ll}
1 & k
\end{array}\right] z_{2}+z_{5}+q k z_{6}\right) \\
& s_{7}=f_{3}\left(z_{3}+z_{4}\right) \\
& s_{8}=f_{4}\left(z_{7}+z_{8}\right) .
\end{aligned}
$$

(A3a)

(A3b)

(A3c)

$(\mathrm{A} 3 \mathrm{~d})$
The new vector of mating type frequencies has components

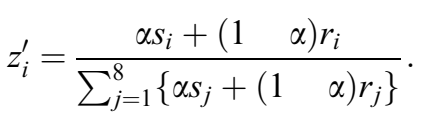

